\title{
THE USE OF BADGES AND ITS IMPACT ON THE INTERACTION DYNAMICS OF A MOOC
}

\author{
Inês Araújo, University of Coimbra, Carlos Santos, Luís Pedro, University of Aveiro,
} Portugal

\begin{abstract}
Several research projects have been using gamified approaches as a way to develop media and information literacies in particular cohorts. Badges are one of the elements that is often used in these approaches and its importance and scope has been widely discussed in the realm of Educational Technology. In the scope of the GamiLearning project, a gamification strategy was designed using the badges' engine of the SAPO Campus platform in order to provide continuous training in this field to a group of teachers. The particular training action reported in this article was implemented via the "Badges: how to use?" MOOC. Data obtained shows that the interaction dynamics patterns were very significant between the trainees, especially in terms of posts, comments and endorsements. These results suggest that the use of badges as a motivational asset can contribute to a more sustained engagement of students throughout the duration of the training action and, hence, to a greater ratio of completion of MOOCs. This article will present the data obtained in this MOOC and will promote a discussion about the motivational affordances of the use of badges in educational contexts.
\end{abstract}

Keywords: MOOC, badges, motivation, teacher education

\section{Introduction}

Gamification is a term that has been pervading the educational jargon in the last few years. In fact, it has been so used in the educational field that researchers have found worth producing meta-analysis and systematic mapping studies (Dicheva \& Dichev, 2015) about it. Studies analysed indicate that "gamification in education is still a growing phenomenon, [but] the review reveals that (i) insufficient evidence exists to support the long-term benefits of gamification in educational contexts; (ii) the practice of gamifying learning has outpaced researchers' understanding of its mechanisms and methods; (iii) the knowledge 
of how to gamify an activity in accordance with the specifics of the educational context is still limited" (Dichev \& Dicheva, 2018; p.1).

From our point of view the last point is very serious because it impacts the previous ones. The literature points out that this is a growing concern by educational agents that feel the need to innovate in their classrooms, especially to engage and motivate students in learning activities, but do not have the proper tools and, most importantly, they lack the knowledge to do it. This implies it is needed not only to gain knowledge about gamification, but, foremost, about how to design and apply it in specific contexts (Cózar-Gutiérrez, SáezLópez, 2016).

The gamification term is highly disputed. While it has been consistently used for the past 10 years, there is not an agreement in the literature about its definition and several claims have been made about its nature, boundaries and utility. One of the most cited definitions states that “(...) the use of game design elements in non-game contexts" (Deterding et al., 2011). This apparently simple sentence, however, encloses a great complexity. In order to use these game design elements/components in their activities, practitioners need to know them in detail, distinguish them from other game-related terms such as game mechanics, dynamics, aesthetics (Hunicke, LeBlanc, \& Zubek, 2004) and know their strengths and weaknesses. Badges are one of the aforementioned game design elements. Several studies report the use of these elements in educational activities, usually to recognition, certification and assessment objectives (Gibson, Ostashewski, Flintoff, Grant, \& Knight, 2015).

In this article we argue that the use of badges as a motivational element can be more beneficial and have a greater educational impact than the mere use of these elements as a recognition and validation tool.

\section{Badges: definition and impacts}

Badges have been used for a long time as symbols that convey information about social origin and hierarchical positions (Halavais, 2012). Currently, a "badge is a symbol or indicator of an accomplishment, skill, quality or interest" (Mozilla Open Badges, 2014) and is also commonly associated to the concept of a reward in the context of games.

However, badges are much more encompassing in terms of its applications. In educational contexts badges can assume different functions related to certification, competition, achievement, identification, path orientation, recognition and reward (Araújo, Pedro, Santos, \& Batista, 2018; Halavais, 2012). As their impact is directly dependent on the value that a community attributes them, there is a significant amount of previous work in order to determine the specific function that a community wants to highlight through the 
attribution of badges. As put by Halavais (2012; p.369), "they can serve as a clear way of expressing what is valued by a community".

According to a study by Aldemir, Celik, and Kaplan (2018, p. 246), badges are recognized as assets that can be fun, that can be used as a confidence-booster resource and a feedback agent, being important to learners' self-assessment and that, used in a continuous and systematic way, "might function as a personalized motivator for the students at different skill, knowledge and interest levels (...)”.

\section{The SAPO Campus platform}

SAPO Campus is a digital communication platform developed in the scope of a research and development partnership between the University of Aveiro and several partners of the Portugal Telecom/Altice group (Santos, 2016).

The creation, issuing and endorsement of badges is available in SAPO Campus since 2013. Any administrator may create badges and attribute them to members of the community that he/she thinks are deserving. Members can obviously accept or refuse the badge attribution and can also choose if the badge is visible only in that community context or publicly visible in his/her profile. The badge feature in SAPO Campus has an original functionality that cannot be found in other similar platforms: the possibility of endorsing members through badges. The main issue reported by members was not so much a technical difficulty of creating badges but an actual doubt related to the badge content and its smooth integration in the pedagogical planification of learning activities. Jovanovic and Devedzic, (2015; p.120) also identified this problem: “(...) anyone who ventures in building a non-trivial badge system will probably face a huge badge conceptualization problem: what are the achievements in a specific case, what to badge/reward, under what conditions, and, most importantly, how to chain and prioritize the achievements?". The discussion of these results by the development team led to the decision to build a community in the platform that could provide examples and a discussion space in order to help SAPO Campus' members who wished to use badges in their practices. This community assumed the form of a MOOC, entitled "Badges: how to use?" that is presented in the next section.

\section{The "Badges: how to use?" MOOC}

\section{General description}

The "Badges: how to use" MOOC was conceptualized and offered in the scope of the GamiLearning research project as a way to train teachers in the general gamification field but more prominently to help them plan the use of badges. MOOCs are a way of providing accessible training opportunities so that teachers attending MOOCs would be able to adapt 
to rapid changes that take place in the curriculum, in the school institution, in their own assessment and also in the available technologies (Kleiman, Wolf, \& Frye, 2015). Having that in mind, a MOOC was considered as the adequate modality to offer this training action, aiming to reach different teachers, of all teaching levels and that would be interested in being active members of a learning community in this field, sharing examples, doubts and potential solutions regarding the use of badges.

The MOOC has begun on the $20^{\text {th }}$ of April of 2017, lasted for 6 weeks and had 135 inscriptions. In terms of structure, the indications of Salmon (2003) were followed so the first week was an onboarding and familiarization one with activities that were designed so that members could know each other and also the SAPO Campus platform. During this week members were asked to register and explore the platform, edit their public profile and avatar, to complete a description about themselves and to use the task management tool available in the platform. Finally, members were invited to choose, from a set of badges created to that purpose, a badge to attribute to the presentations/descriptions made in the platform. In the end, the most voted badge would be issued. This particular task was designed to create some affinity between the community members and was very effective as many members not only voted and commented the presentations but also suggested possible situations in which those badges could be used. The following two weeks were dedicated to explore the conceptual aspects that support the use of badges and to present and discuss the state of the art of this field. The tasks suggested assumed the reading of some relevant studies together with some complementary research and information sharing activities. The next two weeks (weeks 3-5) were focused on application scenarios. MOOC participants were asked to conceptualize a badge system that could be used in their teaching activities. In these 2 weeks the nature of the work was essentially hands-on, supported by tutorials specially created for these tasks. The final week (week 6) was a reflexion week. Participants were asked to share some ideas about the importance of this training action, namely what could change in terms of their teaching activities with this new knowledge.

Participants in this MOOC were asked to read the available texts, to share examples they found or that they created related with the use of badges and to participate in the ongoing dialogue through their posts and comments. This typology of participation contributed to a very rich interaction dynamics between $\mathrm{MOOC}$ members. Being a $\mathrm{MOOC}$ about the use of badges that was its main focus and the activities that were planned were designed so that the participants, in a first instance as students and later as teachers, could feel the impact these elements can have in an online learning community. As mentioned earlier, the first task was to recommend a badge to the presentation of a MOOC participant colleague. Later, badges were issued recognizing the conclusion of a weekly task and the 
participation in the synchronous sessions. In the badge creation phase participants could also create their own badges and issue them directly to their colleagues. These experiences allowed MOOC participants to experience and apply the concepts that were discussed.

\section{The MOOC's badge system}

A set of badges was created for this particular MOOC to reach the following objectives

- To promote the curiosity about badges and the interaction between MOOC members;

- To provide a rich contact experience with badges;

- To recognize and give feedback to the tasks performed by the members;

- To highlight important aspects related to the use of badges in the course of the activities;

- To certify the conclusion of the MOOC.

Table 1 presents a detailed description of the plan of badges attribution in the MOOC. It should be stressed that, at least, a badge was attributed each week, signalling the conclusion of that week's activities. Throughout the MOOC it was possible to provide to each member a direct contact with different types of badges, making it easy to bridge more conceptual issues with practical use that arise with the use of badges.

Table 1: "Badges: how to use?" MOOC activities and weekly attributed badges

\begin{tabular}{|c|c|c|}
\hline Week & Main activities & Badge objective \\
\hline $1^{\text {st }}$ & $\begin{array}{l}\text { Presentation } \\
\text { To endorse a badge to attribute to each } \\
\text { presentation }\end{array}$ & $\begin{array}{l}\text { To provide a rich first experience with badges } \\
\text { To identify MOOC members To promote } \\
\text { interaction between } \mathrm{MOOC} \text { members }\end{array}$ \\
\hline $2^{\text {nd }}$ & $\begin{array}{l}\text { Readings and reflective comments on those } \\
\text { readings To choose a badge from a pool of } \\
\text { examples sharing the justification for that choice }\end{array}$ & $\begin{array}{l}\text { To know about the conceptual framework } \\
\text { underlying the use of badges } \\
\text { Badge that recognizes the } \\
\text { conclusion of the } 2 \text { nd week activities }\end{array}$ \\
\hline $3^{\text {rd }}$ & $\begin{array}{l}\text { Readings and reflective comments on those } \\
\text { readings Sharing of ideas about the use of each } \\
\text { badge type }\end{array}$ & $\begin{array}{l}\text { To understand the several possibilities of using } \\
\text { badges Badge that recognizes the conclusion } \\
\text { of the 3rd week activities }\end{array}$ \\
\hline $4^{\text {th }}$ & $\begin{array}{l}\text { Tutorial related to the creation of badges in } \\
\text { different platforms } \\
\text { To create a badge and share it in the platform } \\
\text { Synchronous discussion about the work developed }\end{array}$ & $\begin{array}{l}\text { To plan and to create a badge To promote the } \\
\text { attribution of badges between the participants } \\
\text { Badge that recognizes the conclusion of the } \\
\text { 4th week } \\
\text { activities }\end{array}$ \\
\hline $5^{\text {th }}$ & $\begin{array}{l}\text { Create a badge system Synchronous discussion } \\
\text { about the work developed }\end{array}$ & $\begin{array}{l}\text { To plan a badge system Badge that recognizes } \\
\text { the conclusion of the } 5 \text { th week activities }\end{array}$ \\
\hline $6^{\text {th }}$ & $\begin{array}{l}\text { Training evaluation } \\
\text { Synchronous discussion about the work developed }\end{array}$ & $\begin{array}{l}\text { To finish the activities } \\
\text { To certify the conclusion of the MOOC through } \\
\text { the attribution of an Open Badge }\end{array}$ \\
\hline
\end{tabular}




\section{Method}

This study applied Social Network Analysis (SNA) metrics on all the interaction data extracted from the "Badges: how to use?" MOOC. This method allows the use of metrics that afford the study of interaction in online communities as well as its graphic representation through graphs and sociograms. In these, people are represented as nodes and the edges represent the connections between nodes (community members). Besides the graphical representation it is possible to extract metrics that are grouped in cohesion measures, measures of centrality and measures of formation of communities. For this article, the following metrics should be taken into account (Ferreira, 2016):

- Diameter - it represents the maximum distance between any two nodes in a graph.

- Density - it represents the cohesion level of a community and varies between 0 and 1. Communities with a density closer to 1 are more cohesive.

- Degree - it represents the number of ties each node has with other nodes in the graph. In-degree is a measure that counts the number of nodes directed to a given node and out-degree is the number of nodes a given node directs to.

- Betweenness - it represents the number of paths between nodes that pass through a given node.

Data collected corresponds to the notifications issued by the notification engine of the platform related with publications, comments, blog posts, favourite contents, file and image sharing, link publishing and badge endorsements and awards. Each register has information about the community member that was the source of the interaction, of the target member(s) of that action, as well as the date in which the notification was created and the type of interaction that it represents. We considered relevant to attribute different weights to each type of interaction. Hence, values between 1 and 135 were attributed taking into account that the community had 135 participants.

\section{Results}

A csv file with the columns target, source, data, relationship type and weight was analysed, following the procedures of previous studies that used this method of data extraction from the SAPO Campus platform (Cabral, 2016; Ferreira, 2016; Pedro et al., 2016, Araújo et al. 2018). Using the Gephi application, a graph was then created (cf. Figure 3) using the Force Atlas 2 algorithm in which the edges that represent the interactions between nodes reflect the weight values defined. In terms of the distribution of the interaction by week/month, it is visible that interactional values were evenly distributed during the 6 weeks of the MOOC (cf. Figure 2). A peak in the "badge_endorse" interaction type is visible in the beginning of the second week (20-26 April) that corresponds to the particular task that was to be completed in that date. This steady pattern somehow contradicts the phenomenon of 
"funnel of participation" reported in some studies as there is not a decrease of participation throughout the different phases of the MOOC (Clow, 2013).

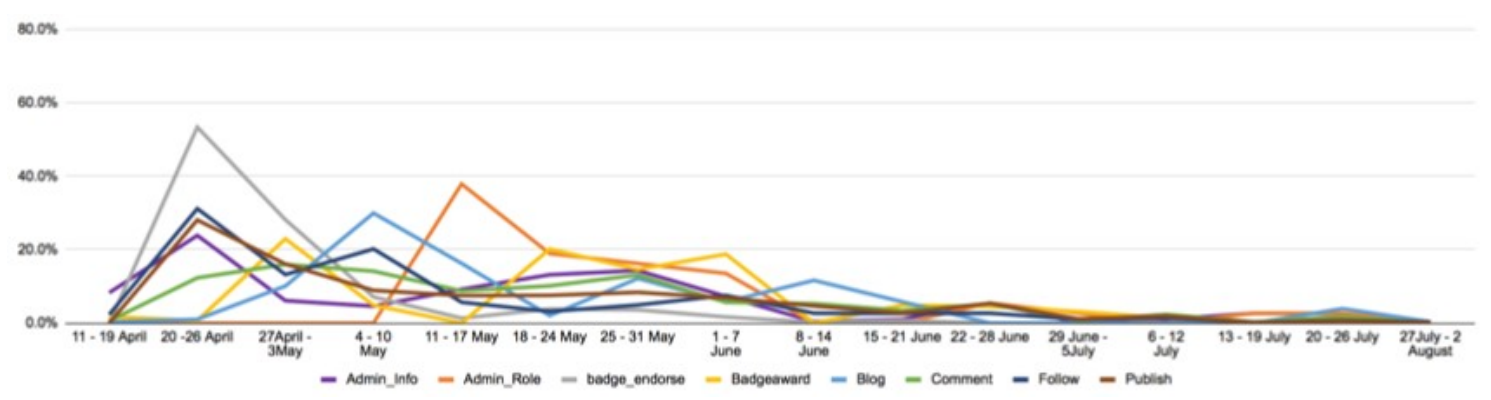

Figure 2. Evolution of the percentage of interaction types by week.

One interesting aspect is also related with a peek in terms of the "admin_role" interaction type, beginning in the fourth week and until the sixth week. This peak matches the activity of planification of the badge system that implied a deeper engagement of the community members, namely in terms of sharing ideas and asking for advice. Generically, Figure 2 shows that the main interaction peaks were achieved in the weeks in which the planned activities implied a given action by the MOOC participants. This evolution of specific interaction types is also visible in a detailed analysis of the month of May (cf. Figure 3).

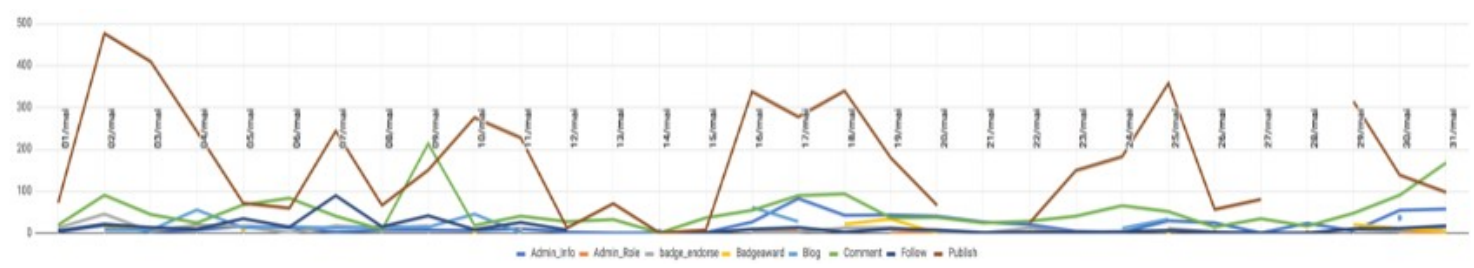

Figure 3. Evolution of the percentage of interaction types by day (May).

The peak moments are visible and match specific dates in which activities such as the delivery of outputs or synchronous discussions were scheduled. The peaks happen in successive days followed by a stagnation period (weekends), showing that interaction types such as "blog_articles" and "comment" are somewhat restrained to workdays. This pattern is not very different from what is reported in other studies regarding interaction in MOOCs (Wong et al., 2015). The data obtained allows us to claim that socializing activities are more conducive to participation and interaction. More, strong values of interaction and engagement are particularly associated with motivational activities, such as the ones related with badges' endorsement and sharing of ideas related to a potential badge system. In terms of social network analysis metrics, the values obtained show that this community has a diameter value of 2 . This is a strong indicator of proximity between the participants as it means that from any node in the network it is possible to reach another node having only one node as broker of that connection. In terms of density, the network has a value of 0.448 showing an average cohesion level. Finally, the average degree of the network is 59.53 
which means that, on average, each member of the community interacted with $\sim 60$ members.

\section{Conclusions}

The results obtained in this study show that activities designed with the objective of motivating participants to interact in the learning community resulted in relevant levels of engagement. In terms of participation types, these activities included not only badges' endorsement activities but also discussions related to design thinking activities (creation of a badge system) and its connection to specific educational contexts.

When compared with other types of activities, such as guidance activities recurring to readings and tutorials, engagement levels were not found to be very high. One must be cautious in establishing a cause-effect relationship between the use of badges and the increase of motivation, however. The literature confirms that claim: "[a]lthough the connection between motivation and gamification design is demonstrated by a number of the reviewed studies, they do not add persuasive evidence confirming the effect of gamification as a motivational tool” (Dichev \& Dicheva, 2018; p.12).

From our point of view this study shows that the use of badges as a motivational element in an educational intervention mediated by technologies can contribute to a more sustained engagement of students throughout the duration of that intervention and possibly generate interaction dynamics patterns conducive to better learning results.

\section{References}

Aldemir, T., Celik, B., \& Kaplan, G. (2018). A qualitative investigation of student perceptions of game elements in a gamified course. Computers in Human Behavior, 78, 235-254. https://doi.org/10.1016/J.CHB.2017.10.001

Araújo, I., Pedro, L., Santos, C., \& Batista, J. (2018). Crachás: como usar em contexto educativo? In M. J. Gomes, A. J. Osório, \& A. L. Valente (Eds.), Challenges 2017: Aprender nas Nuvens, Learning in the Clouds (pp. 159-176). Braga: Centro de Competência em Tecnologias de Informação e Comunicação na Educação (CCTICIEUM). Retrieved from http://hdl.handle.net/10773/21672

Cabral, G. (2016). Exportação de dados para análise de redes sociais: implementação e avaliação de uma ferramenta. MSc dissertation in Multimedia Communication. Aveiro: University of Aveiro. Retrieved from: http://hdl.handle.net/10773/17802

Clow, D. (2013). MOOCs and the funnel of participation. Proceedings of the Third Conference on Learning Analytics and Knowledge (LAK13), 185-189. Leuven, Belgium. 
Deterding, S., Dixon, D., Khaled, R., \& Nacke, L. (2011). From game design elements to gamefulness: defining gamification. Proceedings of the $15^{\text {th }}$ International Academic MindTrek Conference: Envisioning Future Media Environments, 9-15. New York, NY: ACM.

Dichev, C., Dicheva, D. (2018). Gamifying education: what is known, what is believed and what remains uncertain: a critical review. International Journal of Educational Technology in Higher Education, 14, 9. https://doi.org/10.1186/s41239-017-0042-5

Dicheva, D., Dichev, C. (2015). Gamification in education: where are we in 2015? Proceedings of the World Conference on E-Learning (ELEARN 2015), Kona, Hawaii, October 19-22, 1276-1284. Chesapeake: AACE.

Ferreira, M. (2016). SAPO Campus: aprendizagem, ensino e pessoas em rede. Phd thesis in Multimedia in Education. Aveiro: University of Aveiro. Retrieved from: http://hdl.handle.net/10773/15855

Gibson, D., Ostashewski, N., Flintoff, K., Grant, S., \& Knight, E. (2015). Digital badges in education. Education and Information Technologies, 20(2), 403-410. https://doi.org/10.1007/s10639-013-9291-7

Halavais, A. M. C. (2012). A Genealogy of Badges: Inherited meaning and monstrous moral hybrids. Information, Communication \& Society, 15(3), 354-373. https://doi.org/10.1080/1369118X.2011.641992

Hunicke, R., LeBlanc, M., \& Zubek, R. (2004). MDA: A Formal Approach to Game Design and Game Research. Proceedings of the AAAI workshop on Challenges in Game. US: AAAI Press.

Jovanovic, J., \& Devedzic, V. (2015). Open Badges: Novel Means to Motivate, Scaffold and Recognize Learning. Technology, Knowledge and Learning, 20(1), 115-122. https://doi.org/10.1007/s10758-014-9232-6

Kleiman, G. M., Wolf, M. A., \& Frye, D. (2015). Educating Educators: Designing MOOCs for Professional Learning. In Paul Kim (Ed.), Massive Open Online Courses: The MOOC Revolution (pp. 117-146). New York: Routledge. https://doi.org/10.4324/2F9781315848655-13

Mozilla Open Badges. (2014). Badges. Retrieved October 19, 2016, from https://wiki.mozilla.org/Badges

Pedro, L., Santos, C., Batista, J., Cabral, G., Pais, F., \& Costa, C. (2016). Social network analysis and digital learning environments: a framework for research and practice using the SAPO Campus platform. Proceedings of the INTED2016 Conference, Valencia, Spain, 1061-1070. 
Salmon, G. (2003). E-moderating: The Key to Teaching and Learning Online (2 ${ }^{\text {nd }}$ ed.). London: Routledge Falmer.

Santos, C. (2016). Estudo, concepção e desenvolvimento de uma plataforma integrada de serviços web 2.0 para utilização em contexto de ensino superior. Phd thesis in Information and Communication in Digital Platforms. Aveiro: Universidade de Aveiro. Retrieved from http://ria.ua.pt/handle/10773/18603

Wong J., Pursel B., Divinsky A., \& Jansen B. (2015). An Analysis of MOOC Discussion Forum Interactions from the Most Active Users. In N. Agarwal, K. Xu, \& N. Osgood (Eds.), Social Computing, Behavioral-Cultural Modeling, and Prediction (pp. 452-457). SBP 2015. Lecture Notes in Computer Science, vol 9021. Springer. 